\title{
Modelling Molecular Mechanisms: A Framework of Scientific Reasoning to Construct Molecular-Level Explanations for Cellular Behaviour
}

\author{
Marc H. W. van Mil • Dirk Jan Boerwinkel • Arend Jan Waarlo
}

Published online: 14 August 2011

(C) The Author(s) 2011. This article is published with open access at Springerlink.com

\begin{abstract}
Although molecular-level details are part of the upper-secondary biology curriculum in most countries, many studies report that students fail to connect molecular knowledge to phenomena at the level of cells, organs and organisms. Recent studies suggest that students lack a framework to reason about complex systems to make this connection. In this paper, we present a framework that could help students to reason back and forth between cells and molecules. It represents both the general type of explanation in molecular biology and the research strategies scientists use to find these explanations. We base this framework on recent work in the philosophy of science that characterizes explanations in molecular biology as mechanistic explanations. Mechanistic explanations describe a phenomenon in terms of the entities involved, the activities displayed and the way these entities and activities are organized. We conclude that to describe cellular phenomena scientists use entities and activities at multiple levels between cells and molecules. In molecular biological research, scientists use heuristics based on these intermediate levels to construct mechanistic explanations. They subdivide a cellular activity into hypothetical lower-level activities (top-down approaches) and they predict and test the organization of macromolecules into functional modules that play a role in higherlevel activities (bottom-up approaches). We suggest including molecular mechanistic reasoning in biology education and we identify criteria for designing such education. Education using molecular mechanistic reasoning can build on common intuitive reasoning about mechanisms. The heuristics that scientists use can help students to apply this intuitive notion to the levels in between molecules and cells.
\end{abstract}

M. H. W. van Mil ( $\square)$

Molecular Cancer Research, University Medical Centre Utrecht, Universiteitsweg 100, 3584 CG

Utrecht, The Netherlands

e-mail: M.H.W.vanMil@UMCUtrecht.nl

M. H. W. van Mil · D. J. Boerwinkel · A. J. Waarlo

Freudenthal Institute for Science and Mathematics Education, Utrecht University, Princetonplein 5, 3684 CC Utrecht, The Netherlands 


\section{Introduction}

Many biological disciplines have extended their scope towards the molecular level. This 'molecularization' of biology (Kay 1996; Morange 1998, p. 172) adds molecular-level details to phenomena that traditionally have been studied only at higher levels, such as embryology, neurobiology and evolution. Our understanding of many biological phenomena that until recently could be described only at the level of the population, whole organisms or cells is now revolutionized with new insights at the macromolecular level (Moore 1993).

In upper-secondary biology education, this macromolecular level is part of the curriculum. Students learn the structure and properties of DNA, RNA and proteins and they are taught how DNA codes for RNA and proteins. However, according to Duncan and Reiser (2007) they are not explicitly taught how this knowledge can be used when explaining phenomena at the level of the cell or higher levels of biological organization.

For instance, in genetics education, it appears that the molecular details of DNA and proteins add very little to students' understanding of genetic phenomena. Lewis and Kattman (2004) report that the majority of British students in their study (age 14-16) state that genes are important for the determination of characteristics. However, most students did not appear to hold any coherent understanding of the biological mechanisms by which this might be achieved. They report that students treat genes as small particles containing a trait or characteristic and they discuss the implications for education when students take this notion with them in further study (Lewis and Kattman 2004). Marbach-Ad and Stavy (2000) report similar findings. In their study, many students used concepts and terms from the molecular level such as gene and DNA, but they were unable to explain mechanisms and intermediate stages that link genes to the biological phenomena they are involved in. Furthermore, less than half of the 12th graders in their study were able to explain the function of RNA. These and many other studies (e.g. Duncan and Reiser 2007; Venville and Treagust 1998) show that students have difficulty understanding how genes determine traits, even after they have been taught how genes code for proteins via RNA. One of the problems in upper-secondary genetics education is that the message about gene function appears to be twofold: classical genetics education emphasizes that genes determine hereditary traits, whereas in molecular genetics education the message is that genes code for proteins. Although these two accounts of gene function are related, it appears to be very difficult for students to combine the two messages into one overall framework that makes gene function intelligible (see also Lewis and Kattman 2004). Duncan and Tseng (2011) stress that to understand the relationship between genotype and phenotype it is critical to understand that the genetic code does not directly specify observable effects, but that these effects are driven by interactions at lower organizational levels. Current genetics education, being focused mainly on memorization of terms and processes (AAAS 2005; Duncan and Reiser 2007; Verhoeff et al. 2009), fails to connect the molecular level to higher-level phenomena. Students in undergraduate life sciences curricula encounter similar problems (Duncan 2007).

To link genes with traits, at least three distinct 'how' questions are needed. To understand 'how genes determine traits', one needs to understand 'how genes code for proteins', 'how proteins are involved in cellular processes' and 'how cellular processes contribute to phenomena at higher levels of biological organization'. Not all of these 'how' questions are unfamiliar to students in upper-secondary education. The first 'how' question is answered by the central dogma in molecular genetics, i.e. that genes code for proteins via the processes of transcription and translation. Several teaching strategies have been 
developed to teach this central dogma, and it is a standard part of upper-secondary biology curricula in the Netherlands and many other countries. The third 'how' question concerns the ability to connect different levels of organization in biology. The importance of the notion of organizational levels has been stressed by many authors (e.g. Duncan 2007; Knippels 2002; Rappoport and Ashkenazi 2008; Verhoeff et al. 2008; Wilensky and Resnick 1999), and educational strategies such as the 'yo-yo strategy' by Knippels (2002) have been developed to enhance students' ability to connect different levels of organization. The second 'how' question also concerns connecting levels, in this case connecting the cellular level to the molecular level. However, the relationship between molecules and cells is not straightforward. Cellular processes can hardly ever be explained by the action of single genes and proteins; rather, the concerted action of many macromolecules brings about an effect at the cellular level (Boogerd et al. 2007).

The studies of Marbach-Ad and Stavy (2000) and Duncan and Reiser (2007) have provided strong indications as to why detailed information about genes and proteins does not automatically help students to explain how genes function: students consider the macromolecular level in the cell as a collection of very complex chemicals (Dreyfus and Jungwirth 1990), but they might miss what Morange (2008) calls the 'molecular vision'. This vision entails the idea that behaviour of the living cell emerges from the orchestrated functioning of macromolecules (Morange 2008). As Dupré (2009, p. 43) puts it: “One cannot infer the behaviour of a cell by treating it as a bag of chemicals...'. Discrete biological function can only rarely be attributed to an individual gene product, in the same sense that the main function of haemoglobin is to transport gas molecules in the bloodstream (Hartwell and Hopfield 1999). Most biological functions arise from interactions of many components; they are system-level properties instead of properties of individual gene products. Duncan and Tseng (2011) indeed identify that students lack a robust understanding of the functioning of proteins as parts in complex systems when reasoning about genetic phenomena. They stress the need for a framework for reasoning about complex systems that can help students to understand how cellular phenomena can emerge from the interactions of molecules in general and proteins in particular.

\section{Aim and Approach of the Study}

Molecular and cell biologists study the behaviour of macromolecules within the context of a living cell and they try to discover the relationships between these levels of biological organization. Mental models and heuristics that experts use can be informative for designing education (Glaser 1999). Therefore, we suggest that if we characterize more precisely what these scientists present as explanations and how they construct these explanations, this might help educators to better design education that links molecular interactions to cellular processes. In this study, we thus seek to formulate educational design criteria based on the analysis of the goals and strategies in molecular and cell biology research.

The research questions in this study are:

1. What characterizes scientific explanations that aim at understanding cellular processes in terms of molecular interactions?

2. Which heuristics are used to construct these explanations?

3. What educational design criteria can be derived from the analysis of these scientific explanations and heuristics? 
We present a literature review on the philosophical foundations of molecular biology and the closely related fields of molecular cell biology and molecular systems biology. The philosophy of science is concerned with both the nature of scientific explanations and the strategies scientists use to construct these explanations. Based on the philosophy of molecular biology, we propose a framework representing the characteristics of molecular explanations of cellular processes. Heuristics used to construct these explanations can also be represented in this framework. Research on the process of bacterial chemotaxis will serve as an example to show that our findings reflect scientific practice and that historical and contemporary scientific explanations of chemotaxis fit in our framework. The framework aims to provide criteria for the design of educational activities that help students to connect cellular-level phenomena to the molecules that constitute the cell.

\section{Explanations and Heuristics in Molecular and Cell Biology Research}

\subsection{Explanations in Biology}

Characterizing scientific explanations has been focus of philosophical attention and debate throughout history. Woodward (2010) provides an overview of models of scientific explanations and the historical developments starting from the deductive-nomological (DN) model (Hempel and Oppenheim 1948) that shows how laws of nature play a central role in scientific explanations. The D-N model has received criticism, and different accounts of scientific explanations have been developed since then. Attempts to unify these different accounts of explanations over different scientific disciplines raised the debate in the philosophy of biology about the status of biology as an autonomous discipline (Mayr 1996). One of the issues still the subject of a lively debate is the question of whether biological explanations can be reduced to explanations in chemistry and/or physics (see, for instance, Fox Keller 2009; Dupré 2009). Both Fox Keller and Dupré claim to be materialists. Fox Keller (2009 p. 21) states that 'as a materialist I am committed to the position that all biological phenomena, including evolution, require nothing more than the working of physics and chemistry', and Dupré formulates his standpoint as: 'I do not believe there is any kind of stuff in the world other than the stuff described by physics and chemistry' (Dupré 2009, p. 33). We subscribe to this materialist view. However, this view does not imply that all biological explanations can be replaced by the type of explanations used in chemistry and/or physics. Both Fox Keller and Dupré deny that all biological explanations could be derived from the theories or laws of physics or chemistry. This issue of theory reduction has been subject to debate in the philosophy of science for many years, and the dominant view within the philosophy of biology is that no such derivation is possible (Dupré 2009). To clarify the focus of our study, we will give a brief overview of different types of biological explanation by characterizing the types of questions biologists try to answer. Then we can specify what type of questions molecular and cell biologists try to answer as a starting point to characterize the type of explanations that connect cellular and molecular-level phenomena.

Mayr (1961) first made the crucial distinction between evolutionary (or ultimate) and functional/developmental (or proximate) explanations, as answers to 'Why?' and 'How?' questions. The functional biologist Mayr 'is vitally concerned with the operation and interaction of structural elements. His ever-repeated question is "How?" How does something operate, how does it function?' (Mayr 1961, p. 134). Mayr uses the questionword 'why?' to refer to evolutionary explanations in biology. 'Why' in this case is a 
synonym for 'How did the phenomenon come to be, in the light of evolution?' Ariew (2003) reconsiders Mayr's 'ultimate/proximate' distinction and he specifies more precisely the different types of questions that 'evolutionary' and 'proximate' explanations provide answers to. According to Ariew, evolutionary explanations answer questions about the prevalence and maintenance of traits in the population such as 'Why is something prevalent?' and 'Why will something continue to persist?' Proximate explanations answer causal questions about developmental and physiological processes. They are causal as they issue in functional analyses of a system's causal capacities (including developmental analyses) whereby the function of a trait is its causal capacity. Proximate explanations thus answer questions such as 'How does something get built?' and 'How does something operate?' What Ariew calls the functional analyses of a system's causal capacities (how does something operate?) is in line with Cummins' characterization of functional analysis: 'To ascribe a function to something is to ascribe a capacity to it which is singled out by its role in an analysis of some capacity of a containing system' (Cummins 1975 p. 765). Note that in addition to functional analyses Ariew includes developmental analyses (how does something get built?) in his account of proximate cause. According to Ariew, functional and developmental explanations together form a category of individual-level causal explanations that answer questions about an organism over its lifetime. This contrasts evolutionary explanations that answer population-level questions about the diversity of life over many generations.

\subsection{Mechanistic Explanations in Molecular and Cell Biology}

In the introduction, we concluded that explanations of systemic properties at the cellular level in terms of the behaviour of the molecular component within that system are effectively missing in current biology education. These types of explanations are typically proximate explanations; they try to answer the question 'how does the system operate?' These are causal explanations that are constructed from functional analyses of the causal roles of proteins as parts in complex systems (Boogerd et al. 2005; Craver 2001; Cummins 1975). Boogerd et al. (2005) conclude that explanations of systemic properties are typically mechanistic explanations. In their analysis of the upcoming field of systems biology, Boogerd et al. (2007) conclude that the search for explanations for systemic properties can be characterized as the attempt to construct mechanistic models of the behaviour of the system. Darden (2006) shows that contemporary biologists indeed often seek to discover mechanisms, and Bechtel and Abrahamsen (2005) also state that the term biologists most frequently invoke in explanatory contexts is 'mechanism'. Both Bechtel and Abrahamsen (2005) and Machamer, Darden and Craver, abbreviated as MDC (Machamer et al. 2000), argue that this concept of 'mechanism' is central for the philosophical understanding of the biological sciences.

The importance of mechanisms in biology and molecular biology in particular was stressed by several authors in the early days of molecular biology (Bechtel and Richardson 1993; Brandon 1984; Burian 1996; Crick 1988; Kauffman 1970; Wimsatt 1972), but it has only received serious attention in the philosophy of science since MDC's publication (Machamer et al. 2000). Since then, the amount of literature on what is called 'the new mechanistic perspective' (Darden 2007) is rapidly growing. Mechanistic explanations play a central role not only in molecular biology (see Darden and Craver 2002) and molecular systems biology (Boogerd et al. 2007) but also in all other 'molecularized' disciplines such as cell biology (Bechtel 2006), immunology, neurobiology (Craver 2002), developmental biology and evolution (Skipper and Millstein 2005). 
Darden (2008) emphasizes that the work on mechanisms in philosophy of biology did not originate as a response to past work in philosophy in science but from considerations of the work of biologists themselves, especially in molecular biology, biochemistry and cell biology. She confirms that the philosophical work on mechanisms reflects the research goals and activities that are recognizable in the way biologists work and communicate about their work. Several authors have used historical reconstructions to show that indeed the scientific discourse in molecular biology and related fields can be characterized as a search for mechanisms. Gilbert and Mulkay (1984) reconstructed the quest for the molecular mechanism responsible for ATP synthesis based on interviews with the scientists involved. Their work clearly shows that alternative models of possible mechanisms coexisted and that experimental results contributed to the refinement of one model while weakening the plausibility of others. Darden and Craver (2002) applied the MDC framework (Machamer et al. 2000) to the case of the discovery of the mechanism of protein synthesis, and Craver (2002) describes the experimental strategies to construct multi-level mechanisms in the neuroscience of memory.

When looking at review articles in molecular and cell biology, the central role for mechanistic models is easily recognizable. In many articles, models of mechanisms are summarized in graphical representation (Bechtel and Abrahamsen 2005). An example of such a representation can be found in Fig. 1. It is adapted from a review article (Baker et al. 2006) that summarizes the current state of knowledge of the process of bacterial chemotaxis The figure shows a simplified representation of the mechanistic model, which explains how bacteria can change the direction of their movement depending on the availability of nutrients. Scientists have been working on the mechanistic explanation for this process since the early 1960s and the model is still being refined.

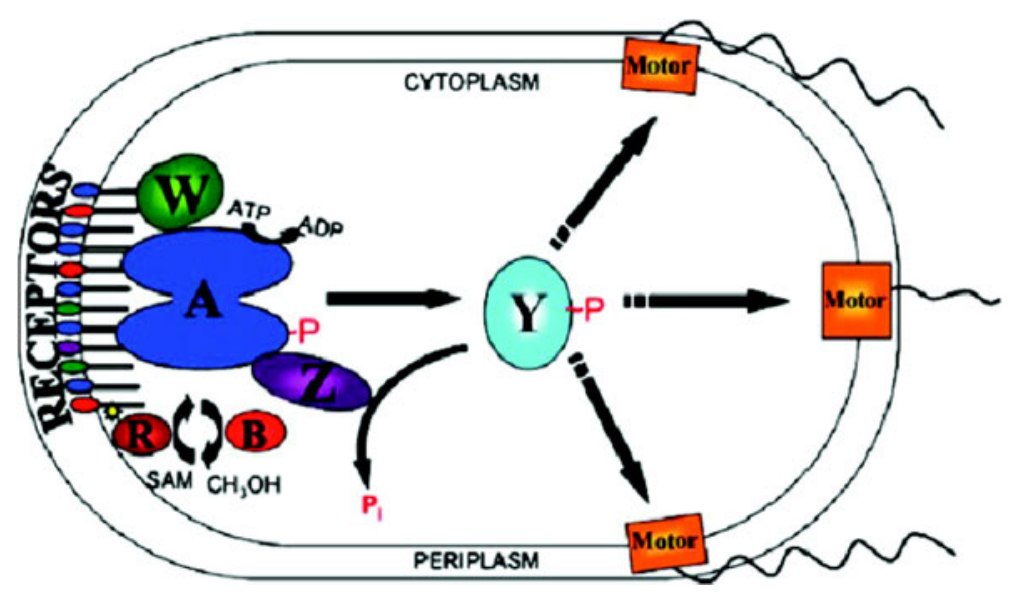

Fig. 1 Model of the mechanism of bacterial chemotaxis as presented in Baker et al. (2006). After binding attractant or repellent molecules, the receptors activate intracellular proteins that mediate the level of phosphorylated CheY protein (depicted as Y-p). High concentrations of phosphorylated CheY change the rotation of the molecular motor that drives the flagella. This causes the bacterium to start tumbling instead of swimming smoothly, thereby changing its orientation 
The example of chemotaxis shows the role of the mechanistic model in molecular biology research: the mechanistic model aims to explain the phenomenon by describing how the orchestrated activities of its components bring about the phenomenon (Bechtel and Abrahamsen 2005; Glennan 2002; Machamer et al. 2000).

\subsection{Structure of Molecular Mechanistic Explanations}

Having said that mechanistic explanations play a central role in molecular biology, we will first elucidate the definition of mechanism used in this paper. Then we will show how mechanistic explanations connect phenomena at the cellular level with the molecules involved in the phenomenon. The definition of a mechanistic explanation used in this paper is based mainly on the work of Machamer et al. (2000). In their publication, they describe mechanisms as follows: 'Mechanisms are composed of both entities (with their properties) and activities. Activities are the producers of change. Entities are the things that engage in activities. The organization of these entities and activities determines the ways in which they produce the phenomenon.' Glennan (2002) and Tabery (2004) emphasize that activities only take place due to the interaction of entities. We include the term interaction in our account of mechanism to emphasize that an entity can have the capacity to display a certain activity but that the actual activity only takes place when the entity interacts with another entity with the appropriate properties. At the molecular level, the entities typically engaging in mechanisms are the gene product (proteins, RNAs) interacting with each other, with DNA and with all sorts of small metabolites. Molecular activities are typically ascribed to gene products. For instance, if a protein catalyses the hydrolysis of ATP, ATPase activity is assigned to this protein. An inventory and categorization of activities of gene products can be found in the Gene Ontology database (Ashburner et al. 2000). General activities ascribed to gene products in this database are for example: catalytic activity, binding activity, transporter activity and enzyme regulator activity (www.geneontology.org).

Machamer et al. (2000) stress that 'Entities often must be appropriately located, structured, and oriented, and the activities in which they engage must have a temporal order, rate, and duration.' Bechtel and Abrahamsen (2005) also emphasize the central role of organization in the mechanisms. Organization of entities and activities specifies when and where the entities and activities are present. Darden (2008) specifies in more detail the organizational features of mechanisms, based on the case of molecular biology. Table 1 shows the features of temporal organization (when) and spatial organization (where) that Darden specifies. Organization can only be assigned to the entities and activities when they are part of the mechanism as a whole. In molecular biology research, hypotheses about the organization of entities and activities are formulated and tested, sometimes even without knowing the exact properties of the entities and activities involved. We therefore explicitly include the term 'temporal and spatial organization' of entities and activities in our description of mechanistic explanations.

Mechanisms are active and productive (Bogen 2008), i.e. the interactions of entities lead to a series of activities because they change the properties or the organization of entities, thereby causing new activities. The overall activity of the mechanism can be defined as the overall change between setup and termination conditions. The use of setup and termination conditions when describing biological mechanisms is a simplification, as many biological mechanisms have a cyclic nature and most mechanisms are part of larger dynamic systems that continuously adapt to changes. For instance, in the case of chemotaxis, the mechanism will never 'start' or 'finish'. The chemotaxis mechanism is continuously active, even in the 
Table 1 Organizational features of entities and activities in mechanistic explanations (adapted from Darden 2008)

\begin{tabular}{|c|c|c|}
\hline \multicolumn{2}{|c|}{ Spatial arrangement of entities and/or activities } & \multirow{2}{*}{$\begin{array}{l}\text { Example in cell biology } \\
\text { Receptor proteins are located at } \\
\text { the plasma membrane }\end{array}$} \\
\hline Localization & Where are the entity and/or activity located? & \\
\hline Structure & Are entities grouped into physical structures? & $\begin{array}{l}\text { Histone proteins are grouped } \\
\text { into nucleosomes }\end{array}$ \\
\hline Orientation & $\begin{array}{l}\text { How are entities positioned relative to other } \\
\text { entities? }\end{array}$ & $\begin{array}{l}\alpha \text { - and } \beta \text {-Tubulin heterodimers } \\
\text { are positioned plus end to minus } \\
\text { end in microtubules }\end{array}$ \\
\hline Connectivity & What entities and/or activities are connected? & $\begin{array}{l}\text { G-protein-coupled receptors } \\
\text { connect to G-proteins when } \\
\text { activated }\end{array}$ \\
\hline Compartmentalization & $\begin{array}{l}\text { Are entities and activities located in } \\
\text { compartments? }\end{array}$ & $\begin{array}{l}\text { ATP synthase enzymes are } \\
\text { located in mitochondria }\end{array}$ \\
\hline Temporal aspects of e & atities and/or activities & Example in cell biology \\
\hline Order & $\begin{array}{l}\text { In what sequence are activities and entities } \\
\text { present? }\end{array}$ & $\begin{array}{l}\text { Ribosomes cannot assemble } \\
\text { until the small subunit binds a } \\
\text { mRNA molecule }\end{array}$ \\
\hline Rate & At what rate or speed do activities take place? & $\begin{array}{l}\text { Conversion rate of ADP into } \\
\text { ATP by ATP synthase enzymes } \\
\text { depends on the concentration of } \\
\text { protons }\end{array}$ \\
\hline Duration & How long are activities and/or entities present? & $\begin{array}{l}\text { In a signalling cascade } \\
\text { downstream signals depend on } \\
\text { the duration of receptor } \\
\text { stimulation }\end{array}$ \\
\hline Frequency & $\begin{array}{l}\text { Are activities and entities present at a certain } \\
\text { frequency? }\end{array}$ & $\begin{array}{l}\text { The frequency in the activity of } \\
\text { cyclin-dependent kinases } \\
\text { depends on the presence of } \\
\text { different cyclin proteins during } \\
\text { the cell cycle }\end{array}$ \\
\hline
\end{tabular}

absence of attractant or repellent chemicals. Chemical interactions with the receptors just lead to a different productivity, i.e. the motor starts rotating the other way around.

Craver (2001) emphasizes the multi-level nature of biological mechanisms. He shows that multi-level mechanisms can be presented in terms of hierarchically organized entities and activities. An entity that displays a certain activity at level L consists of lower-level entities that display certain activities at level $\mathrm{L}-1$. At the same time, the entity at level $\mathrm{L}$ is part of a higher-level entity at level $\mathrm{L}+1$ that displays its activity because of the organized activities of the entities at level L. Richardson and Stephan (2007) also stress that mechanistic explanations connect entities at different levels of biological organization, and that the hierarchical ordering of entities is typically in terms of part/whole relationships.

In Fig. 2, we present the general account of mechanistic explanations we will use in this paper. We adopt the MDC approach (Machamer et al. 2000) of hierarchically organized entities and activities to describe multi-level mechanisms, with the following additions. In our model, we explicitly separate organization from the entities and activities. We also separate interactions from activities, although the two are causally linked. Furthermore, we emphasize that activities produce change in the organization and properties of entities, thereby causing the productive continuity that constitutes the higher-level activity. 


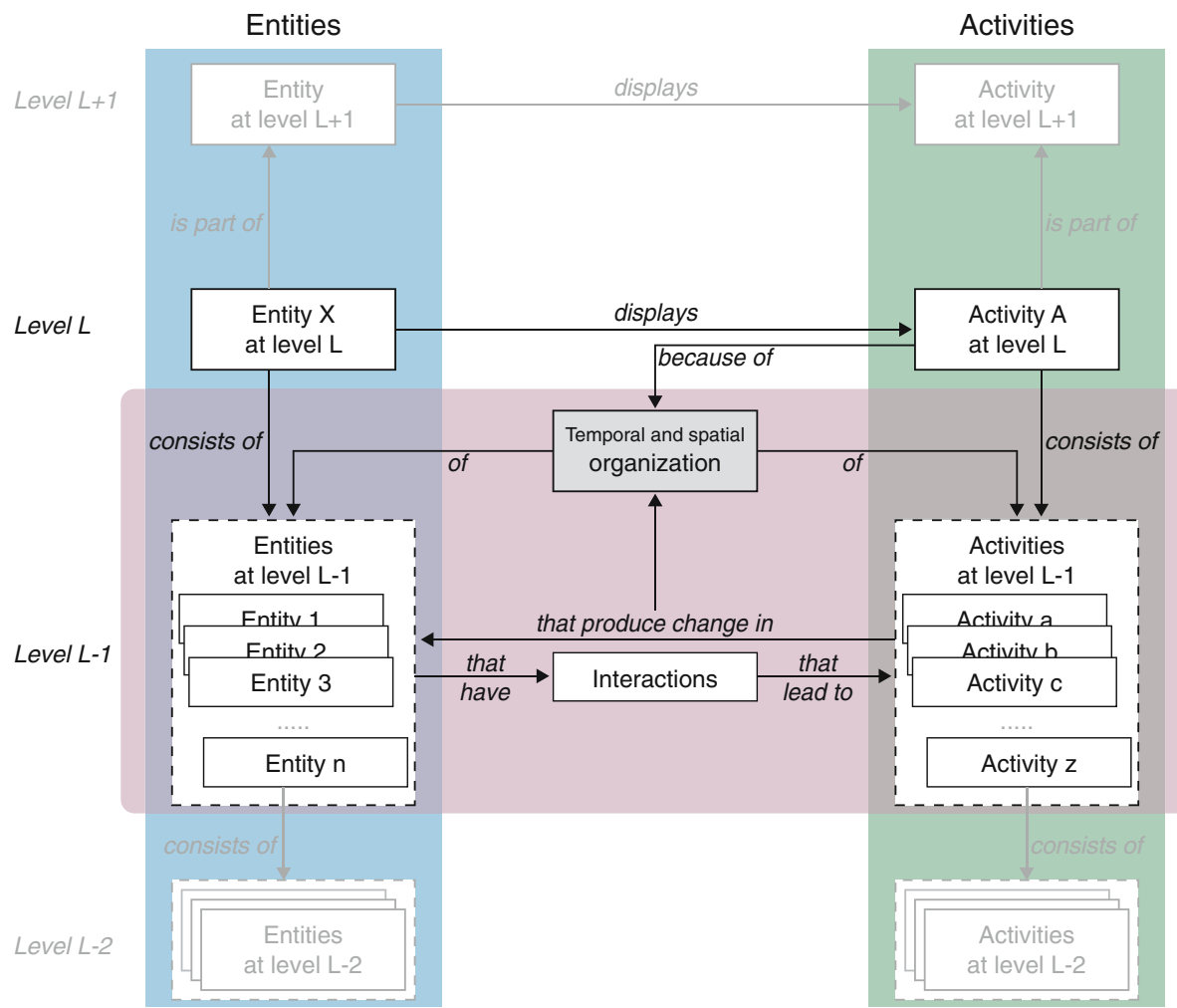

Fig. 2 General structure of multi-level mechanistic explanations that consist of hierarchically organized entities and activities

In biology in particular, most mechanistic explanations span multiple levels. What entities and activities are studied at what level of organization depends on the research goals and varies among biological disciplines. In molecular biology, explanations typically describe the activities and organization of molecules in the cell to explain certain activities in the cell. Activities at the cellular level are often described with the cell as the subject; for example, the cell divides, the cell metabolizes glucose, the cell moves. Activities at the molecular level, for example protein activities, are typically formulated with a molecule as the subject; for example, the receptor binds a hormone or the enzyme hydrolyses ATP. Protein activity starts with the protein binding one or more other molecules. This causes the protein to change conformation, thereby allowing new intra- or intermolecular chemical bonding. The subsequent chain of breaking and forming of chemical bonds in and between the molecules ends in a relatively stable state in which the protein, its binding partner(s) or both have undergone molecular changes. The difference between the condition before interaction and the relatively stable condition after interaction is what is called the molecular activity. In the case of enzyme activity, the substrate is changed while the enzyme typically returns to its original conformation, whereas in other protein activities, such as binding of a ligand to a receptor, the protein remains in a changed conformation, as long as its binding partner stays bound. In either case, the changes caused by one molecular activity are prerequisite for subsequent activities within the mechanism; in other words, the termination conditions of one activity form the starting condition for the 
next. Alberts' metaphor (Alberts 1998) of viewing a cell as a factory that contains a network of interlocking assembly lines in which protein machines do the job stems from this mechanistic view on protein function.

Molecular biologists try to find molecular-level explanations for cellular activities, but hardly any cellular activity can be explained by the activity of a singular protein or other molecule. Most cellular activities arise from interactions among many components. Hartwell and Hopfield (1999) introduce the term 'functional module' as a critical level of organization in between cells and molecules. These modules have discrete functions in the cell that arise from the interactions among their molecular components (proteins, DNA, RNA and small molecules). By definition, a functional module is a molecular ensemble whose function is separable from those of other modules. It is constituted from a fraction of the cell components that together form a discrete functional entity. As examples of such functional entities, Hartwell and Hopfield (1999) presents ribosomes as well as signal transduction cascades. In the case of ribosomes, the functional module is a structural unit, spatially separable from other cell components, while in the case of a signal transduction cascade, the module is not a fixed structure but a highly dynamic, transient interplay between a set of proteins. Although the cell contains many structural elements, varying from protein complexes of a few proteins to huge organelles composed of thousands of different molecules, Hartwell and Hopfield (1999) stress that what is considered a functional module does not depend on the size, structure or complexity of the molecular ensemble. A group of cell components, either being proteins, protein complexes or (parts of) organelles, can be considered a functional module when the components work together to accomplish a relatively autonomous function in the cell. Assigning modular activities is thus a form of functional analysis (Cummins 1975) of the cell's components. Some modules, such as ribosomes, have a relatively stable organization during function, while others, like signal transduction pathways, are highly dynamic and transient molecular ensembles, not detectable as a structural unit in the cell. In line with the framework of mechanistic explanations presented in Fig. 2, functional modules can be considered as entities even though many modules are not stable structures. Here the term 'entity' refers to the molecular ensemble as a whole, to which a certain modular activity can be assigned. To characterize modules as 'entities' displaying specific 'modular activities' makes it possible identify organizational levels in between cells and molecules based on the function of groups of cell components. These functional levels offer an alternative to the structural subdivision into organelles traditionally used in upper-secondary cell biology text books.

In the case of bacterial chemotaxis, this functional analysis would lead to the following reasoning: if the bacterial cell moves towards more favourable locations, then there must be a group of molecules in the cell that together constitute a functional module that moves the cell towards more favourable locations. This is what is depicted in Fig. 1 as the chemotaxis system. Note that in this figure the components of chemotaxis are not all depicted in terms of individual molecules. What is assigned the 'motor' is in itself a collection of many molecules that together display motor activity. Here we see that the overall entity (the chemotaxis system or module) is functionally dissected into smaller modules. In the case of chemotaxis, the overall system constitutes a sensor module, a signalling module and a motor module. We use the term submodules (Hofmann et al. 2006) to stress that modules in the cell can be functionally subdivided into smaller modules down to the level of the macromolecules. Scientists often use these intermediate levels between cells and molecules to describe what kind of activities take place in the cell. For example, the terms 'transcription' and 'DNA replication' refer to modular activities, and 'transcription machinery' (Orphanides and Reinberg 2002) and 'replication machinery' (Alberts 2003) refer to the functional modules that carry out these functions. 
If we apply this account of cellular, modular and submodular, and molecular levels to our framework of multi-level mechanisms, this results in a schema (Fig. 3) that explains the connections between the entities, activities and organization at the different levels from cells to molecules. In Fig. 4, we present the same figure elaborated for bacterial chemotaxis. Note that we have included only molecular interactions in the figures and have left out modular and submodular interactions. Although modules have interactions in the sense that the output of one module serves as input for another module, these inputs and outputs are themselves molecular interactions that can be described in terms of the molecules of one module that interact with molecules of the other. In the case of chemotaxis for instance, the receptor molecules in the sensor module interact with the CheA protein in the signalling module, and the CheY protein in the signalling module interacts with a protein in the motor module (Baker et al. 2006).

Note that Fig. 1 (cartoon-like) and Fig. 4 (multi-level) both present in a simplified way the current state of knowledge of molecular explanations for bacterial chemotaxis behaviour. For many cellular processes, only partial molecular explanations are available. Some activities can be specified in terms of molecular activities, while others can be described only in functional terms that specify higher-level activities. In other cases, the involvement of molecules in a process is known but the connection to other molecules and the positioning in the intermediate levels is far from understood. Scientists try to fill these

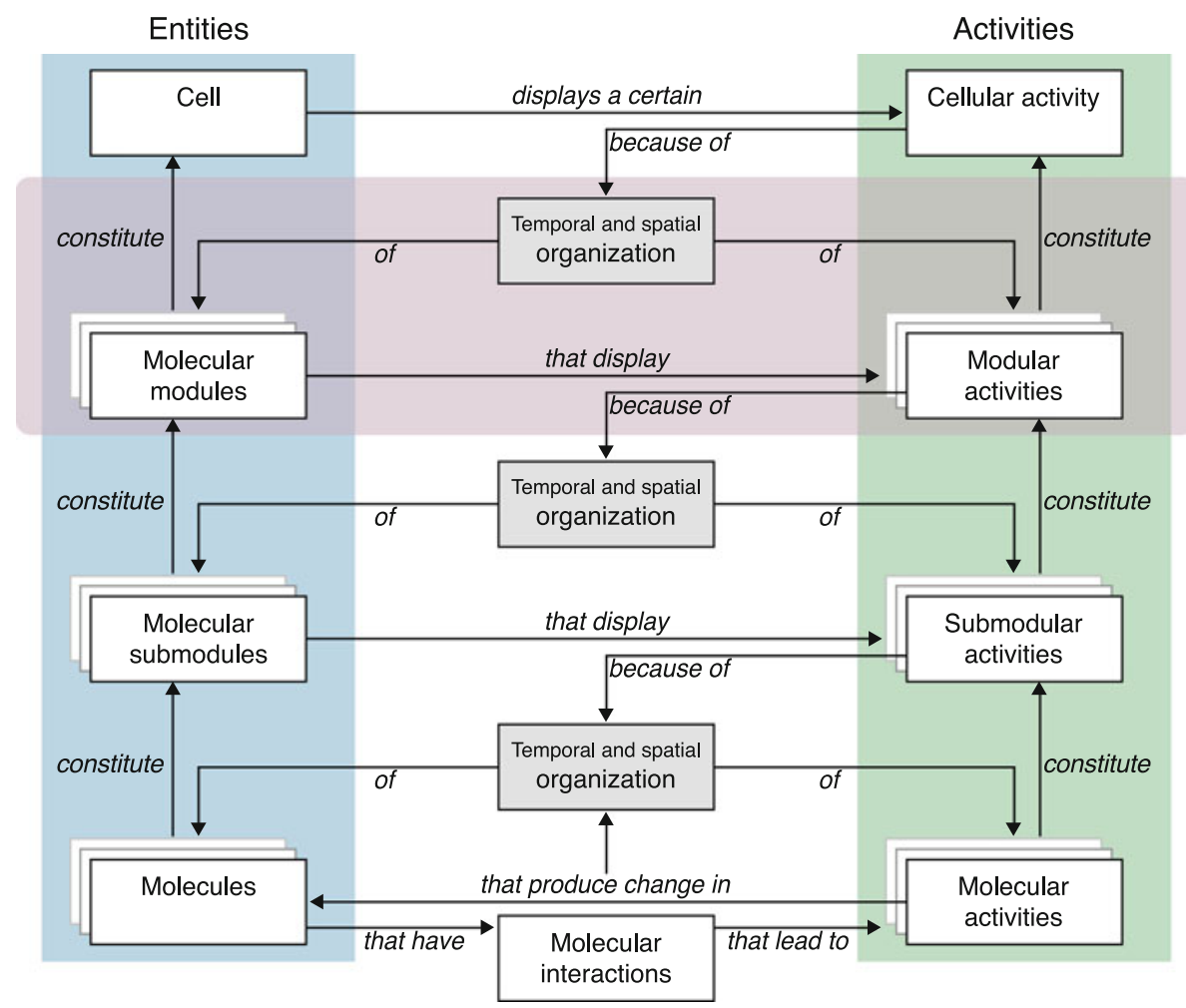

Fig. 3 A multi-level mechanistic explanation describes a cellular activity in terms of the properties, activities and organization of interacting modular, submodular and/or molecular entities 


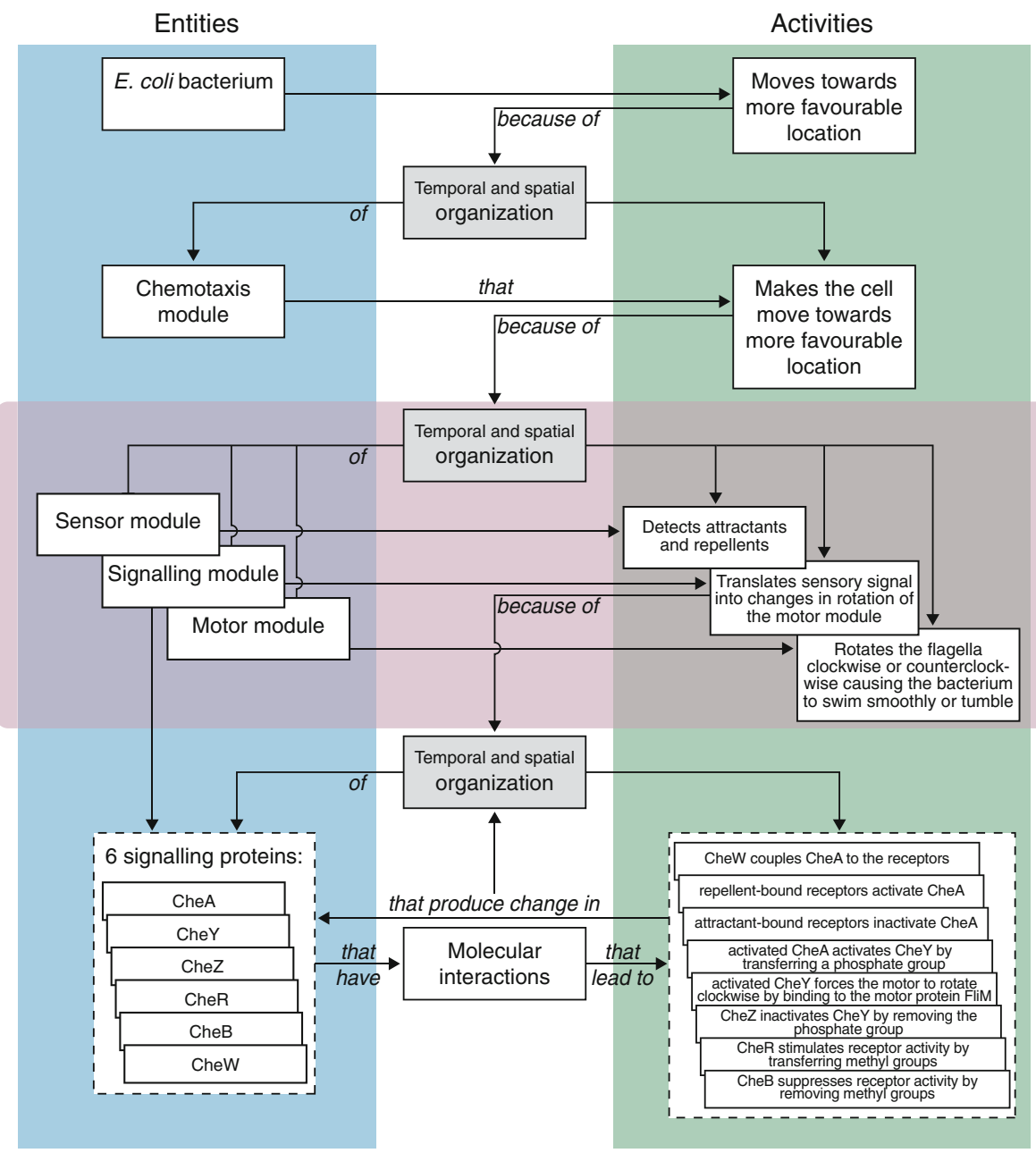

Fig. 4 Multi-level mechanistic explanation of the chemotaxis behaviour of an E. coli bacterium, elaborated from the signalling module down to and including the molecular level. Data on temporal and spatial organization are not detailed in this figure

gaps by gathering new information that can be placed in one of the boxes represented in Fig. 3. The question remains as to which heuristics and experimental strategies scientists use in their search for new information that can be added to the mechanistic explanation they are working on.

\subsection{Heuristics to Construct Molecular Mechanistic Explanations}

According to Darden (2002) scientists' strategies are aimed at discovering entities and activities and defining the relationships between them and their spatial and temporal organization, thereby filling the gaps between setup and termination conditions of the mechanism. One must find an activity for each entity and an entity for each activity. Also 
Bechtel and Abrahamsen (2005) conclude that strategies to construct mechanistic explanations follow directly from the conception of mechanism as described in Fig. 2: the scientist must identify the parts in the mechanism, determine what activities they perform, and figure out how they are organized so as to generate the phenomenon.

\subsubsection{Formulating Mechanistic Research Questions}

Bechtel (2006) and Darden (2006) show that molecular and cell biologists typically search for mechanistic explanations. This central aim provides a first heuristic used by these scientists, since it specifies the type of research questions they formulate. Their everrepeated question is 'How does it work?' Early work on chemotaxis offers a nice example of the mechanistic research questions that scientists formulate to better understand the phenomenon they study. Adler (1975) presents six 'how' questions that need to be answered to provide a mechanistic explanation of chemotaxis:

1. How do individual bacteria move in a gradient of attractant or repellent?

2. How do bacteria detect the chemicals?

3. How is the sensory information communicated to the flagella?

4. How do bacterial flagella produce motion?

5. How do flagella respond to the sensory information in order to bring about the appropriate change in direction?

6. How is the information integrated, in the case of multiple or conflicting sensory data?

Note that all six questions ask for explanations of activities. The activities to be explained can be recognized by the verbs 'move', 'detect', communicate' 'produce', 'respond', 'bring about' and 'integrate'. Question 1 asks for a description of the overall chemotaxis activity in terms of the behaviour of the cells. Philosophers writing about mechanism stress that describing the phenomenon under study in terms of the activity that the overall mechanism displays is a first and essential step in constructing mechanical explanations (Darden 2002; Richardson and Stephan 2007). In the case of chemotaxis, the behaviour of motile bacteria responding to environmental cues was described by the end of the nineteenth century by Pfeffer (1884), Engelmann (1881) and other biologists. These observations were the starting point for Adler's effort in the 1960s to unravel the underlying mechanism (Adler 1966).

\subsubsection{Functionally Subdividing the Overall Activity}

In questions 2, 3 and 4, Adler divides the total activity into partial activities that together make up the total chemotaxis activity. He hypothesizes that there are three modules with distinct activities: a sensor module that detects chemicals, a signalling module that communicates sensory information and a motor module that produces motion. The strategy of functionally subdividing the overall activity into partial activities that are carried out by lower-level modules is a research strategy that Darden (2002) calls 'modular subassembly'. Hypothesizing these modules can be inspired by analogous modules or types of modules, and experiments can confirm or refute the existence of these types of modules. In the case of chemotaxis, Alder's hypothesis concerning a signalling module that functions more or less separately from the sensory module was supported by experiments with mutant bacteria. It was observed that many mutants lacked the ability to respond to one specific chemical but responded normally to others, while a few of his mutants did not respond to any chemical. Adler concluded that the 


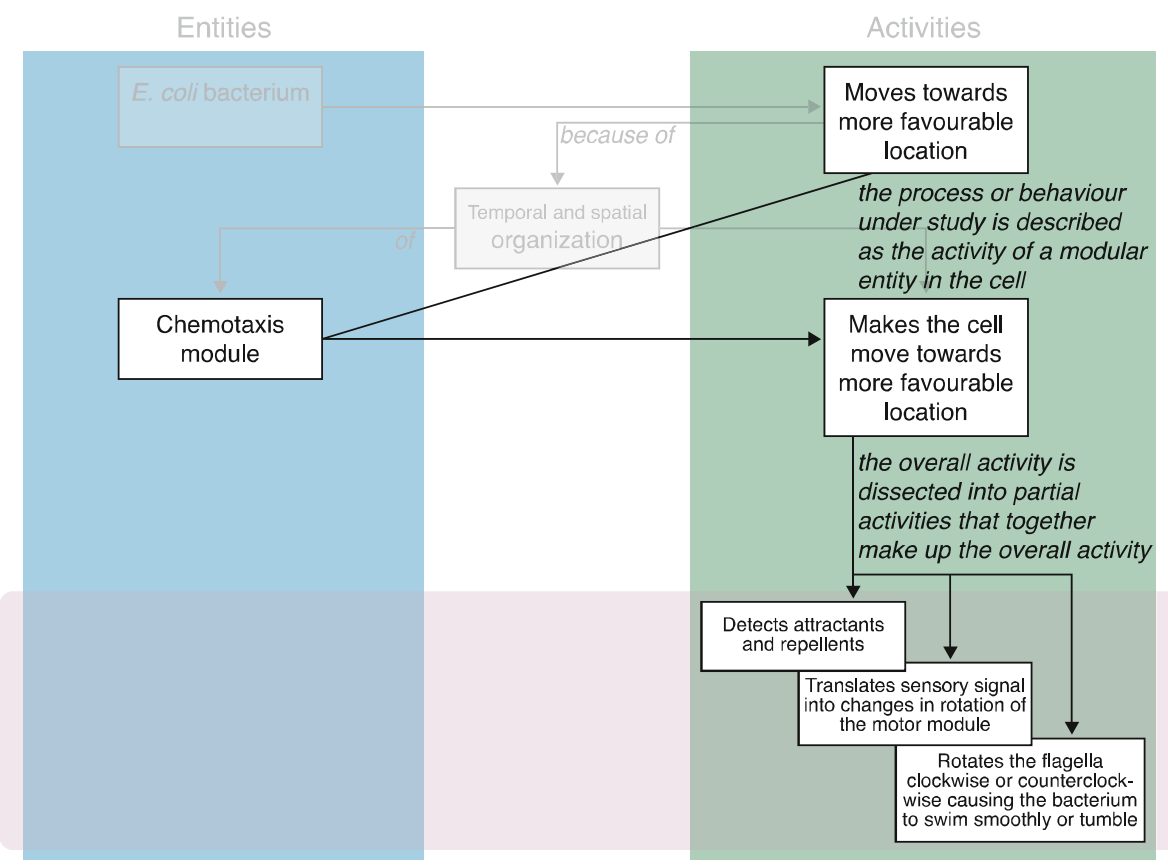

Fig. 5 The strategy of modular subassembly in chemotaxis research: first, the overall behaviour is described as the activity of a modular entity and then this modular activity is functionally subdivided into partial activities

former lacked specific types of sensors in their sensor module, while in the latter, signalling of all sensors was blocked because of an error in the signalling module. In more recent review articles, this distinction into three modules is still used in the descriptions of the mechanism of chemotaxis (e.g. see Baker et al. 2006). Figure 5 shows the strategy of first describing the overall behaviour as an activity of a modular entity in the cell, followed by dissecting this activity in submodular activities.

\subsubsection{Hypothesizing Mechanistic Schemas from Activities}

When Adler started studying chemotaxis, no mechanisms or components of the mechanisms were known. To answer the question of how chemicals are detected, he postulated two possible mechanisms: either the attractants themselves are detected, or the attractants are first metabolized and then some metabolite of the attractant is detected. By analysing the chemotactic activity of mutant bacteria, he was able to show that extensive metabolism of the attractants is neither required nor sufficient for chemotaxis. Without knowing any of the molecular components in the mechanism, he could demonstrate that there must be entities located in the cell membrane that directly sense attractants, which he called 'chemoreceptors'. With this conclusion, the first partial sketch of the mechanism was postulated (see Fig. 6).

As shown in this example, predictions can be made about the properties of entities in the mechanism even without knowing its exact composition. This is a reasoning strategy that Darden (2002) calls 'schema instantiation'. First, a rather abstract draft of the mechanistic 


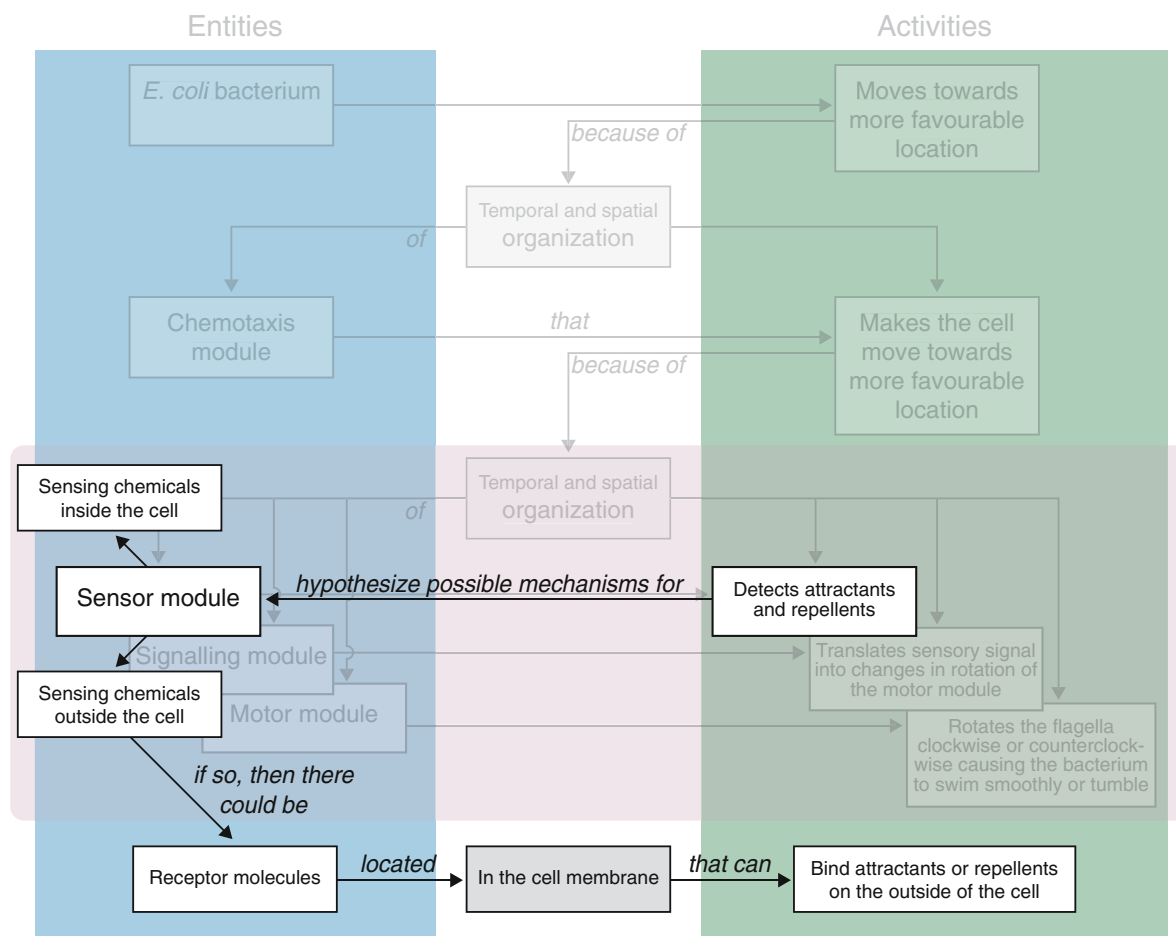

Fig. 6 The strategy of hypothesizing possible mechanisms to explain the sensing of chemicals in chemotaxis research

description of an entity, which she calls a schema, is proposed by considering the behaviour and constraints of the entity as a whole. This schema is then gradually specified and adapted based on experimental results. The construction of these schemas can be inspired by analogies in similar mechanisms in the same or neighbouring fields of research or in the history of science. They can also be inspired by the roles that hypothetical lowerlevel entities or activities are expected to play. Schema instantiation thus starts by hypothesizing what the entity could look like given the activity it displays. This complements the strategy of subdividing activities because that strategy only provides a subdivision in functional terms, which does not yet contain information about properties of the entities that might display this activity.

\subsubsection{Predicting Molecular Properties from Activities and Vice Versa}

In the period when researchers were trying to identify the molecular component involved in chemotaxis, they had to analyse mutant bacteria that displayed abnormal chemotaxis behaviour. Mapping of the mutated genes in these bacteria led to the identification of several proteins that were essential in chemotaxis. In this way, more and more molecules were added to the 'parts list' of the chemotaxis mechanism. However, it was not immediately clear which activities the proteins displayed and what the role of these proteins was in the mechanism. In many cases, the properties of the proteins predicted a type of activity they could be involved in, while in other cases experiments revealed the presence of certain 


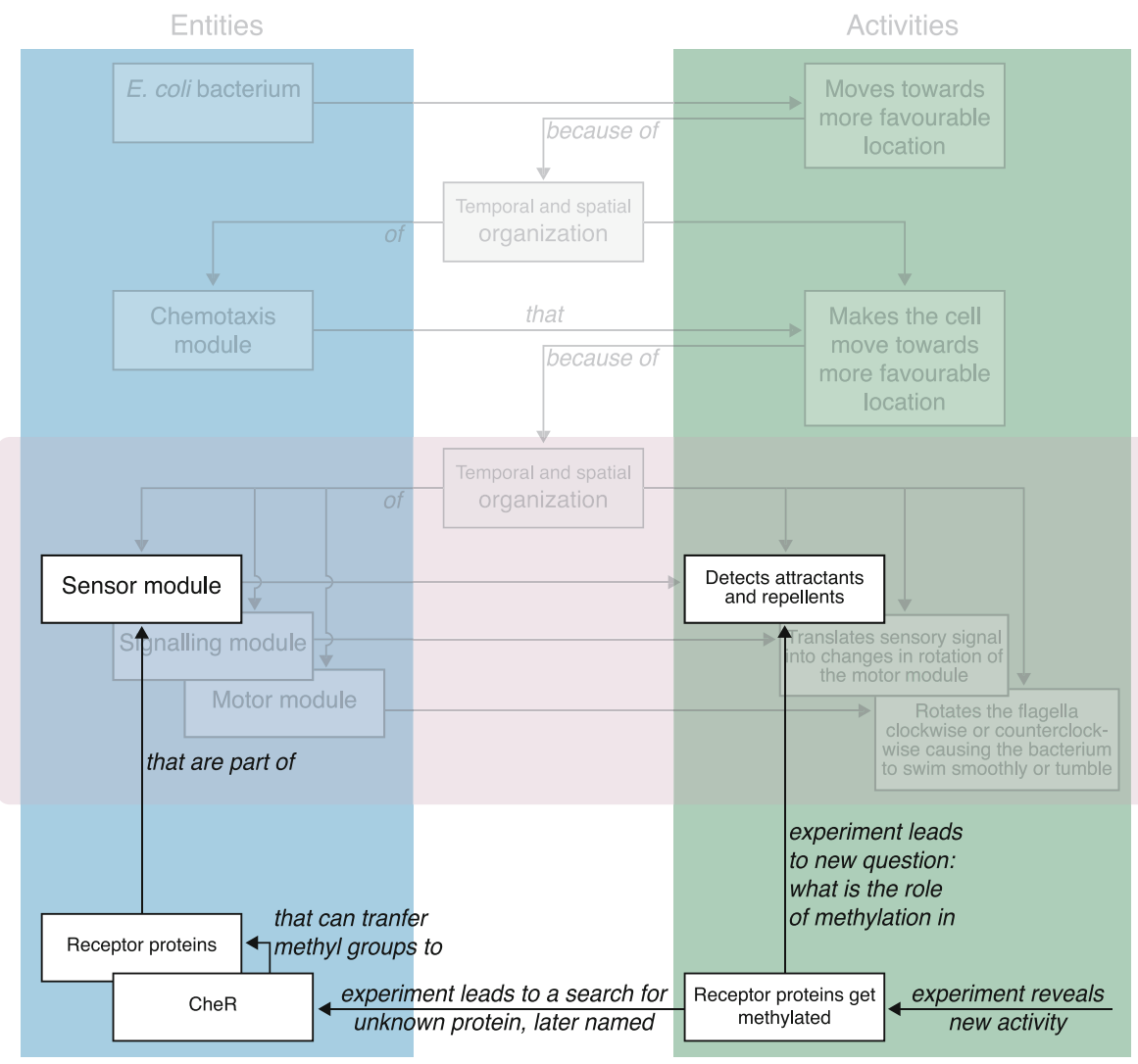

Fig. 7 The strategy of backward chaining in chemotaxis research: finding a new activity in the chemotaxis mechanism leads to the postulation of new entities and their role in higher-level activities

activities that led to the search for a protein that could display this activity. For instance, Silverman and Simon (1977) describe the finding that some of the proteins become methylated. These proteins later turned out to be receptor proteins. The observation that these proteins become methylated led to the search for and identification of chemotaxis proteins that can transfer and remove methyl groups and to new research to find out what the role of methylation in chemotaxis is. The relationship between the identification of this new molecular activity and the research questions it generates is depicted in Fig. 7.

The reasoning strategy in Fig. 7 is an example of what Darden (2002) calls 'backward and forward chaining'. It can help scientists to link molecules to activities and vice versa. Forward and backward chaining is based on the fact that a mechanism has a productive continuity. Interactions of molecules lead to activities and due to these activities the properties and organization of molecules change or new molecules arise. Forward chaining uses the early stages of a mechanism to reason about the types of entities and activities likely to be found in the next stage. Backward chaining reasons from the entities and activities in later stages in the mechanism to predict entities and activities found earlier (Darden 2002). For instance, the identification of a kinase suggests a role for phosphorylated proteins in a later stage in the mechanism (forward), while the identification of phosphorylated proteins suggests kinase activity earlier in the mechanism (backward). 
Both forward and backward chaining can be used to predict activities from identified molecules or to predict properties of molecules from identified activities.

\subsubsection{Hypothesizing and Predicting Organization in the Mechanism}

The strategies identified so far focus on the identification of entities and activities and the relationship between them. However, Bechtel (2006) emphasizes that this is only part of the effort. Both entities and activities are organized within the mechanism. Getting a grip on these organizational aspects within molecular mechanisms is probably most challenging for molecular biologists (Harold 2005). Organizational aspects of entities and activities depend heavily on the mechanism as a whole, and rarely can explanations be given solely in terms of the properties of isolated components (Powell and Dupré 2009). However, the hypothesized mechanisms as well as information on the properties of entities and activities in the mechanism can be of great heuristic value when discovering organizational aspects. For instance, when Adler proposed chemoreceptors to sense the chemicals on the outside of the cell, this immediately implied that these receptors were located in the cell membrane. As the motor modules are located on the other side of the bacterium, somehow components in the mechanism had to transfer the signal from one side of the cell to the other. Years later it appeared that this role is played by CheY proteins that are not membrane bound but diffuse through the cytoplasm from the receptor side of the cell to the motors.

\subsubsection{In Summary}

We identified five heuristics that scientists use to construct mechanistic explanations:

1. Asking how questions.

2. Functionally subdividing activities.

3. Hypothesizing mechanistic schemas.

4. Predicting molecular properties from activities and vice versa.

5. Hypothesizing and predicting organization in the mechanism.

We can conclude that all these heuristics use existing knowledge about activities, entities or organizational aspects to predict and test for unknown activities, entities or organization. The activities, entities and organizational aspects sought can be at the same level, for instance if the chemical properties of a protein predict a molecular activity or its location. But the knowledge at one level can also be used to predict and test activities, entities and organization at higher levels (bottom up) or lower levels (top down). With the goal to fill the gaps and to solve inconsistencies in the model of a multi-level mechanism in the cell, scientists reason back and forth between entities, activities and their organization, and up and down between different levels. As shown with the example of chemotaxis in Figs. 5, 6 and 7, reasoning and research strategies can be displayed in our model of multilevel mechanisms using arrows that connect one box that represents the input information with another one that represents the output information that the strategy aims for.

\section{Mechanistic Reasoning to Fill the Gap Between Cellular and Molecular-Level Phenomena in Biology Education}

Our analysis shows that scientists in molecular biology model molecular mechanisms to explain cellular processes. The first two research questions are: 
1. What characterizes scientific explanations that aim at understanding cellular processes in terms of molecular interactions?

2. Which heuristics are used to construct these explanations?

These can thus be answered as follows:

1. Biological explanations of cellular processes are typically mechanistic explanations. Models of the molecular mechanism explain how a cellular process works by showing how the relationships between the consisting molecular entities, their activities and their spatial and temporal organization together bring about the process. Often intermediate levels are used to show how interacting groups of molecules, called molecular modules, have their own level of organization and fulfil specific functions in the overall process.

2. Five heuristics (summarized in Sect. 3.4.6) show how scientists reason mechanistically between cells and molecules. They formulate mechanistic research questions and model molecular mechanisms to answer these 'how' questions. With the goal being to fill the gaps and to solve inconsistencies in the model, they reason back and forth between molecules, molecular activities and their organization, and they reason up and down between different functional levels between cells and molecules.

In the introduction, we described how relating the cellular level to the molecular level in biology is a crucial but very difficult step for students. Our analysis shows that connecting the molecular and cellular levels entails a form of mechanistic reasoning, because it requires relating the behaviour of wholes at multiple levels to the properties, activities and organization of their parts and vice versa (Machamer et al. 2000). Our characterization of molecular mechanistic explanations and the heuristics that scientists use now makes it possible to reinterpret the problem in terms of students' difficulties in reasoning about molecular mechanistic explanations and thus providing criteria to address them. This brings us to research question 3:

3. What educational design criteria can be derived from the analysis of these scientific explanations and heuristics?

We answer this question by first reinterpreting learning difficulties in terms of the knowledge and reasoning skills needed for reasoning about molecular mechanistic explanations. In the last section we will further specify these needs into educational design criteria by adapting the scientific heuristics identified in Sect. 3.4 for educational use.

We will focus on proteins as the active entities at the bottom level and on protein-based modules at multiple levels between proteins and cells, in line with the work of Duncan and colleagues (Duncan 2007; Duncan and Reiser 2007; Duncan and Tseng 2011). This offers the opportunity to refer explicitly to gene function when discussing mechanisms in the cell, thereby bridging the gap between genes and cells that we identified in the Introduction.

\subsection{Reinterpretation of Students' Learning Problems}

Mechanistic reasoning means reasoning about mechanistic explanations (Russ et al. 2008). We will use the term 'molecular mechanistic reasoning' to refer to the reasoning skills needed to construct and to understand molecular mechanistic explanations. Russ et al. (2008) use a case in physics to show that mechanistic reasoning is abundantly present in student reasoning, even in very young students. Reasoning about mechanisms seems to be quite intuitive. It relates to the question 'How does it work?' Even very young children are 
familiar with the fact that 'wholes' consist of 'parts' and that in many cases interactions of the parts make up the whole. A bike, for instance, can be described mechanistically by describing the parts and their role in the whole (see Grotzer 2003 for a review on young children's appreciation of mechanisms). However, the study of Abrams and Southerland (2001) suggests that mechanistic reasoning in biology education, and especially in molecular biology education, is not as abundantly present as Russ et al. (2008) report. These findings do not necessarily contradict. Mechanistic reasoning is the basis for molecular mechanistic reasoning, but from our analysis we can identify characteristics of molecular mechanistic explanations that complicate students reasoning. These factors may prevent students from using this intuitive notion of mechanism to explain phenomena in the cell.

\subsubsection{Mechanistic Explanations: 'How Does It Work?' is Not an Obvious Question in Cell Biology Education}

For molecular and cell biologists the main question is 'how do cell processes work?' However, Abrams and Southerland (2001) describe how students in the biology classroom tend to neglect physical mechanisms when asked to explain biological phenomena. They tend to focus on the function of a phenomenon, rather than wondering which physical mechanisms explain the phenomenon, and they often rely on teleological and anthropomorphic explanations (Kampourakis and Zogza 2008; Tamir and Zohar 1991; Zohar and Ginossar 1998). In cell biology education, this tendency can be recognized for instance when explaining chromosome transport during mitosis. Most students will be perfectly satisfied with the explanation that chromosomes are sorted and pulled to the centromeres because they need to be distributed equally to form two identical daughter cells. The question how a cell manages to sort and pull chromosomes does not arise in the students' minds. Apparently, the need to explore the causal explanations that answer 'how a cell works' is not self-evident in the biology classroom.

Abrams and Southerland (2001) suggest that one of the reasons for this is the tendency of biology teachers to focus on the benefits of a phenomenon rather than on the cause, and Kampourakis et al. (2011) emphasizes that teachers should be aware of the difference between proximate and ultimate causes to distinguish effectively between 'how?' and 'why?' questions in the classroom.

\subsubsection{Molecular Interactions: Students Do Not Consider Protein Interactions as Basic Causal Events in the Cell}

To be able to reason mechanistically about protein activities in cellular processes, students need to understand that protein interactions can be considered the basic causal events in the cell. As described in Sect. 3.2, protein activities can be understood from the underlying principle that proteins undergo conformational changes when they interact and that these conformational changes allow the next step in the activity of the protein. That means that, in principle, all protein activities can be described causally in terms of the result of binding, changing conformation and breaking and forming chemical bonds. These interactioninduced conformational changes can be considered the basic causal events at the molecular level, comparable to the physical interactions between parts in daily-life machines that cause the machine to function. This machine-like view of proteins is very different from the view of molecules in chemical reactions as taught in traditional chemistry education. Conformational changes play only a minor role in explanations of the simple chemical 
reaction used in the chemistry classroom. We suggest that current education about proteins does not provide students with the ideas that the interaction-induced conformational changes of proteins are the basic causal events in living cells. Upper-secondary biology education focuses on the structural and functional aspects of proteins but fails to show the causality in protein activities.

\subsubsection{Functional Levels: Students are Unfamiliar with the Multiple Functional Levels in Between Cells and Molecules}

In cell biology research, multiple functional levels are distinguished between cells and molecules. Activities at different levels are ascribed to groups of interacting molecules, called functional modules. However, students' images of the inner workings of a cell are based mostly on the structural subdivision of cells consisting of organelles and cytoplasm, since most biology text books present organelles as the organizational level in between cells and molecules. Although organelles are indeed functional units in the cell, only presenting the activities of organelles to explain cellular function has some major disadvantages. First, only part of cellular functions can be assigned to specific organelles. Secondly, many different molecular activities are linked to the same organelle (ATP synthase activity is only one of the many protein activities in mitochondria). Thirdly, the traditional structural subdivision ignores the fact that there are many more functional levels in between cells and macromolecules. Students should be enabled to think up and down between these functional levels to eventually connect activities at the cellular level to molecular activities and vice versa. This bottom-up and top-down reasoning relates to what Knippels calls the 'yo-yo strategy'. She developed this educational strategy to help students to think up and down between levels of biological organization. However, Knippels' strategy was not elaborated for connecting the cellular level to the molecular level. Our framework demonstrates that the traditional levels of cells, organelles and molecules are insufficient to describe how molecules contribute to the functioning of the cell. Knippels' yo-yo strategy can be extended down to the molecular level when cellular activities at the top are viewed as the result of hierarchically ordered mechanisms, with protein activities as the basic units at the bottom and submodular and modular activities as the intermediate levels, necessary to connect these top and bottom activities.

\subsubsection{Molecular Modules: The Abstract, Dynamic and Transient Nature of Molecular Modules Complicates Students' Reasoning}

Scientists identify modules not on structural features but on the discrete functions of groups of molecules. Often these modules are highly dynamic and transient. This complicates reasoning about functional modules, since these cannot always be represented as a structural 'thing'. This abstract and dynamic nature of functional modules adds to the already abstract nature of the macromolecules that constitute these modules. Macromolecules and their activities need to be imagined or represented by using visual modules, such as graphics or animations. Many publications in science education emphasize difficulties related to visualizing abstract concepts such as molecules (Ferk et al. 2003; Gilbert et al. 2008; Mathewson 1999; Michelle et al. 2008; Schönborn and Anderson 2006; Yarden and Yarden 2010). 


\subsubsection{Temporal and Spatial Organization: Students are Unfamiliar with Many Organizational Aspects of Proteins and Protein Activities}

Organization is what distinguishes a mechanism from just a collection of parts. This will not be surprising to students, since the same holds true for any mechanism they know. However, organization in the cell is much more complicated to grasp than the composition of a man-made device. Once assembled, the organization of a man-made device is relatively stable, but as mentioned before, organization in the cell is highly dynamic. One of the aspects of this dynamic nature that is relatively unfamiliar to students is the stochastic nature of protein interactions. Students need to understand that protein activities depend on random collisions to get a grip on the organizational aspects mentioned in Table 1. It explains for instance why the speed and frequency of protein activities is influenced by the concentration of the interacting molecules and it makes intelligible that proteins located in the same compartment will interact when they can move freely, while interactions are limited when proteins are bound to membranes or other structures.

\subsection{From Scientific Heuristics to Design Criteria for Molecular and Cell Biology Education}

In the Introduction, we concluded that students in upper-secondary and even in undergraduate biology education show little awareness that all cellular phenomena emerge from molecular interactions. Although knowledge about the structural and chemical properties of macromolecules is part of most upper-secondary science curricula, students seldom link these properties to the functional roles of molecules in higher-level phenomena (Duncan and Tseng 2011). Here, we restated this problem in terms of difficulties related to multilevel mechanistic reasoning between the cellular and molecular level. From the previous section, we can conclude that these difficulties ask for educational approaches in which:

- Students are guided towards causal-mechanistic instead of functional explanations.

- Students learn how to explain machine-like protein activities from molecular interactions.

- Students are familiarized with the multiple functional levels in between cells and molecules.

- Students are familiarized with the abstract, dynamic and transient nature of molecular modules.

- Students explore the organization of proteins and protein-based modules.

In this section we will further specify these criteria by adapting the heuristics identified in research question 2. These heuristics represent concrete examples of scientists' molecular mechanistic reasoning, and will inform the design of education aiming at the acquisition of this reasoning.

\subsubsection{Raising 'How' Questions About Cellular Activities}

The first heuristic identified shows that the ever-repeated question that molecular and cell biologist ask is 'How does it work?' We discussed in the previous section that this is a question that does not automatically occur to students. We therefore suggest that explicitly raising 'how' questions about cellular activities is an important task for educators in molecular and cell biology. Activities that encourage students to visualize what is actually going on inside a cell might be very useful as a starting point for raising these types of 
questions. More and more animations and graphics are becoming available that show the complexity of living cells (see McGill 2008 for an overview). These animations are visual models and artistic impressions in which choices have been made about how to represent reality. We suggest that discussing what is realistic in these representations and what is not might be very powerful in raising all sorts of 'how' questions when used in the appropriate educational setting.

\subsubsection{Explaining Protein Activities from Molecular Interactions}

The heuristic of predicting activities from molecular properties and vice versa builds on the notion of protein interactions as causal events. For instance, if ATP is involved in an activity, then the protein involved must have a binding site for ATP. The other way around, if the structure of a protein reveals a DNA-binding domain, the protein activity will probably involve the binding of DNA, for instance in transcription activation. These kinds of reasoning exercises to think back and forth between proteins, their interactions and their activities could help students to better understand that protein interactions are the causal events in cellular processes. In the biology classroom, the functioning of proteins can be conceptualized without detailed chemistry, for instance by using the machine metaphor. However, we suggest that at least for a few examples, chemical details must be presented, since forming and breaking chemical bonds in and between molecules is the basis for all conformational changes that are used to explain the machine-like functioning of proteins. Educational activities that show how the same basic chemical principles used in the chemistry classroom can be used to explain how proteins act in a machine-like way might help students to see that basic chemistry can lead to complex machine-like behaviour of proteins and protein-based modules.

\subsubsection{Exploring Levels by Functionally Subdividing Cellular Activities}

We suggest that intermediate levels of functional modules and submodules can form stepping stones when reasoning from molecular to cellular activities and vice versa. If students are trained to use mechanistic reasoning to explore the functional levels between cells and molecules, this could help to make intelligible for them the fact that the interactions of molecules can lead to such complex cellular behaviour. One of the great educational advantages of using intermediate levels of functional modules is that students can hypothesize these functions from cellular activities without detailed molecular knowledge. Starting from a cellular activity, the question to be raised is 'What activities are needed to accomplish this overall activity?' These type of questions resemble the scientific heuristic that Darden (2002) calls 'modular subassembly'. For instance, in the process of cell division, students can hypothesize that the content of the cell must be duplicated, and that the content must be separated into two portions. These two activities are probably too comprehensive to typify them as modular activities but they can be further subdivided, for instance by asking which cellular components should be duplicated. The different components such as DNA, proteins, mitochondria and membranes all have their own duplication mechanisms, some of which could be interesting to elaborate, for example the DNA replication mechanism and the role of DNA polymerase in it. In this way, education about the DNA replication mechanism connects to the overall process of cell division, thereby extending Knippels yo-yo strategy down to the level of molecular activities. 


\subsubsection{Hypothesizing Mechanistic Schemas}

Students may hypothesize about the characteristics of the mechanism by which certain modules function. The question to be raised is: what type of mechanism could accomplish this activity? These hypotheses can be inspired by analogies from daily life. For instance, if, in mitosis, chromosomes are pulled towards the centrioles, this could involve either rail-like mechanisms, pulley-like mechanisms or maybe both. This reasoning strategy resembles the scientific heuristic that Darden calls 'schema instantiation' (Darden 2002).

\subsubsection{Articulating the Role of Organization in Protein-Based Mechanisms}

Identifying how proteins and their activities are organized in protein-based mechanisms is one of the most challenging tasks for scientists. They predict and test organizational aspects from the properties of the proteins (for instance, a DNA-binding domain suggests localization in the nucleus) and they use their hypotheses about the working of the mechanism to predict how parts in the mechanism should be organized. These two strategies can both be used in education to explain that not only is the presence of specific proteins required to establish specific activities in the cell, but also that these proteins have to be organized in a way that makes it possible for the mechanism to function. By exploring the organization of proteins, questions may arise about the origin of the organization of proteins and other cellular components. Some of these questions ask for a developmental explanation. For instance, the question 'What causes this protein to be present in one cell while it is absent in another?' asks for exploring mechanisms of transcription regulation that are central to development. We suggest that educators can use this link between mechanisms and the origin of organization in the mechanisms to show how genes and development are linked.

\subsection{Using Mechanistic Reasoning to Read and Construct Models of Protein-Based Mechanisms}

Mechanistic models and images are not completely unknown in cell biology education. Most upper-secondary curricula already present mechanisms in the cell, mostly by means of cartoon-like models. What has become clear from our research is that students lack the knowledge base to interpret these models correctly, and that therefore presenting these models does not contribute to understanding how molecular interactions explain cellular processes. For instance, arrows in cartoon-like models indicate the activities in the mechanism. Without knowledge of protein interactions, these arrows remain meaningless. Molecular mechanistic reasoning thus allows more adequate interpretations of the molecular graphics and animations already used in education. Furthermore, students may use molecular mechanistic reasoning to generate ideas and hypotheses about the mechanisms underlying biological phenomena that have not yet been explored down to the molecular level. Molecular mechanistic reasoning thus offers students the cognitive tools to fill the gap between the molecular level and higher levels of biological organization.

Designing and testing activities based on the criteria we identified will be the next step to further develop the concept of molecular mechanistic reasoning in molecular and cell biology education. 
Acknowledgments We wish to thank Kees Klaassen for helpful discussion and comments on earlier drafts. This work was supported by grants from the Centre for Society \& Genomics and the Cancer Genomics Centre, both genomics centres of excellence of the Netherlands Genomics Initiative (NGI)/ Netherlands Organisation for Scientific Research (NWO).

Open Access This article is distributed under the terms of the Creative Commons Attribution Noncommercial License which permits any noncommercial use, distribution, and reproduction in any medium, provided the original author(s) and source are credited.

\section{References}

AAAS. (2005). High school biology textbooks: A benchmarks-based evaluation. http://www.project2061. org/publications/textbook/hsbio/summary/genome.htm. Accessed November 30, 2010.

Abrams, E., \& Southerland, S. (2001). The how's and why's of biological change: How learners neglect physical mechanisms in their search for meaning. International Journal of Science Education, 23(12), 1271-1281.

Adler, J. (1966). Chemotaxis in bacteria. Science, 153(3737), 708-716.

Adler, J. (1975). Chemotaxis in bacteria. Annual Review of Biochemistry, 44(1), 341-356.

Alberts, B. (1998). The cell as a collection of protein machines: Preparing the next generation of molecular biologists. Cell, 92(3), 291-294.

Alberts, B. (2003). DNA replication and recombination. Nature, 421(6921), 431-435.

Ariew, A. (2003). Ernst Mayr's 'ultimate/proximate' distinction reconsidered and reconstructed. Biology and Philosophy, 18(4), 553-565.

Ashburner, M., Ball, C. A., Blake, J. A., Botstein, D., Butler, H., Cherry, J. M., et al. (2000). Gene Ontology: Tool for the unification of biology. Nature Genetics, 25(1), 25-29.

Baker, M. D., Wolanin, P. M., \& Stock, J. B. (2006). Signal transduction in bacterial chemotaxis. BioEssays, 28(1), 9-22.

Bechtel, W. (2006). Discovering cell mechanisms: The creation of modern cell biology (Cambridge studies in philosophy and biology). New York: Cambridge University Press.

Bechtel, W., \& Abrahamsen, A. (2005). Explanation: A mechanist alternative. Studies in History and Philosophy of Science Part C: Studies in History and Philosophy of Biological and Biomedical Sciences, 36(2), 421-441.

Bechtel, W., \& Richardson, R. C. (1993). Discovering complexity: Decomposition and localization as strategies in scientific research. Princeton, NJ: Princeton University Press.

Bogen, J. (2008). Causally productive activities. Studies in History and Philosophy of Science Part A, 39(1), $112-123$.

Boogerd, F. C., Bruggeman, F. J., Hofmeyr, J. H. S., \& Westerhoff, H. V. (2007). Systems biology: Philosophical foundations. Amsterdam: Elsevier.

Boogerd, F. C., Bruggeman, F. J., Richardson, R. C., Stephan, A., \& Westerhoff, H. V. (2005). Emergence and its place in nature: A case study of biochemical networks. Synthese, 145(1), 131-164.

Brandon, R. N. (1984). Grene on mechanism and reductionism: More than just a side issue. PSA: Proceedings of the Biennial Meeting of the Philosophy of Science Association, 1984, 345-353.

Burian, R. M. (1996). Underappreciated pathways toward molecular genetics as illustrated by Jean Brachet's cytochemical embryology. In S. Sarkar (Ed.), The philosophy and history of molecular biology: New perspectives (pp. 67-85). Dordrecht, Boston: Kluwer Academic.

Craver, C. F. (2001). Role functions, mechanisms, and hierarchy. Philosophy of Science, 68(1), 53.

Craver, C. F. (2002). Interlevel experiments and multilevel mechanisms in the neuroscience of memory. Philosophy of Science, 69(3), S83-S97.

Crick, F. (1988). What mad pursuit: A personal view of scientific discovery (Alfred P. Sloan Foundation series). New York: Basic Books.

Cummins, R. E. (1975). Functional analysis. Journal of Philosophy, 72, 741-764.

Darden, L. (2002). Strategies for discovering mechanisms: Schema instantiation, modular subassembly, forward/backward Chaining. Philosophy of Science, 69(3), S354-S365.

Darden, L. (2006). Reasoning in biological discoveries: Essays on mechanisms, interfield relations, and anomaly resolution (Cambridge studies in philosophy and biology). Cambridge, NY: Cambridge University Press.

Darden, L. (2007). Mechanisms and models. In D. L. Hull \& M. Ruse (Eds.), The Cambridge companion to the philosophy of biology. Cambridge, NY: Cambridge University Press. 
Darden, L. (2008). Thinking again about biological mechanisms. Philosophy of Science, 75(5), 958-969.

Darden, L., \& Craver, C. (2002). Strategies in the interfield discovery of the mechanism of protein synthesis. Studies in History and Philosophy of Science Part C: Studies in History and Philosophy of Biological and Biomedical Sciences, 33(1), 1-28.

Dreyfus, A., \& Jungwirth, E. (1990). Macro and micro about the living cell: Which explains what?. In P. L. Lijnse, P. Licht, W. de Vos, \& A. J. Waarlo (Eds.). Relating macroscopic phenomena to microscopic particles: A central problem in secondary science education: proceedings of a seminar, Utrecht (pp. 107-118). Utrecht: CDB Press.

Duncan, R. G. (2007). The role of domain-specific knowledge in generative reasoning about complicated multileveled phenomena. Cognition and Instruction, 25(4), 271-336.

Duncan, R. G., \& Reiser, B. J. (2007). Reasoning across ontologically distinct levels: Students' understandings of molecular genetics. Journal of Research in Science Teaching, 44(7), 938-959.

Duncan, R. G., \& Tseng, K. A. (2011). Designing project-based instruction to foster generative and mechanistic understandings in genetics. Science Education, 95(1), 21-56.

Dupré, J. (2009). It is not possible to reduce biological explanations to explanations in chemistry and/or physics. In F. J. Ayala \& R. Arp (Eds.), Contemporary debates in philosophy of biology (pp. 32-47). Oxford: Wiley-Blackwell.

Engelmann, T. W. (1881). Neue methode zur untersuchung der sauerstoffausscheidung pflanzlicher und thierischer Organismen. Pflügers Archiv European Journal of Physiology, 25(1), 285-292.

Ferk, V., Vrtacnik, M., Blejec, A., \& Gril, A. (2003). Students' understanding of molecular structure representations. International Journal of Science Education, 25(10), 1227-1245.

Fox Keller, E. (2009). It is possible to reduce biological explanations to explanations in chemistry and/or physics. In F. J. Ayala \& R. Arp (Eds.), Contemporary debates in philosophy of biology (pp. 19-31). Oxford: Wiley-Blackwell.

Gilbert, G. N., \& Mulkay, M. J. (1984). Opening Pandora's box: A sociological analysis of scientists' discourse. New York: Cambridge University Press.

Gilbert, J., Reiner, M., \& Nakhleh, M. B. (Eds.). (2008). Visualization: Theory and practice in science education. Dordrecht: Springer.

Glaser, R. (1999). Expert knowledge and processes of thinking. In R. McCormick \& C. Paechter (Eds.), Learning and knowledge (pp. 88-102). London: Chapman.

Glennan, S. (2002). Rethinking mechanistic explanation. Philosophy of Science, 69(s3), S342-S353.

Grotzer, T. A. (2003). Learning to understand the forms of causality implicit in scientifically accepted explanations. Studies in Science Education, 39(1), 1-74.

Harold, F. M. (2005). Molecules into cells: Specifying spatial architecture. Microbiology and Molecular Biology Reviews, 69(4), 544-564.

Hartwell, L. H., \& Hopfield, J. J. (1999). From molecular to modular cells biology. Nature, 402(6761), C47.

Hempel, C. G., \& Oppenheim, P. (1948). Studies in the logic of explanation. Philosophy of Science, 15(2), $135-175$.

Hofmann, K. P., Spahn, C. M. T., Heinrich, R., \& Heinemann, U. (2006). Building functional modules from molecular interactions. Trends in Biochemical Sciences, 31(9), 497-508.

Kampourakis, K., Pavlidi, V., Papadopoulou, M., \& Palaiokrassa, E. (2011). Children's teleological intuitions: What kind of explanations do 7-8 year olds give for the features of organisms, artifacts and natural objects? Research in Science Education. doi:10.1007/s11165-011-9219-4.

Kampourakis, K., \& Zogza, V. (2008). Students' intuitive explanations of the causes of homologies and adaptations. Science \& Education, 17(1), 27-47.

Kauffman, S. A. (1970). Articulation of parts explanation in biology and the rational search for them. PSA: Proceedings of the Biennial Meeting of the Philosophy of Science Association, 1970, 257-272.

Kay, L. E. (1996). Life as technology: Representing, intervening, and molecularizing. In S. Sarkar (Ed.), The philosophy and history of molecular biology: New perspectives (pp. 87-100). Dordrecht, Boston: Kluwer Academic.

Knippels, M. C. P. J. (2002). Coping with the abstract and complex nature of genetics in biology education-The yo-yo learning and teaching strategy. Utrecht: CD- $\beta$ Press.

Lewis, J., \& Kattman, U. (2004). Traits, genes, particles and information: Re-visiting students' understandings of genetics. International Journal of Science Education, 26(2), 195-206.

Machamer, P., Darden, L., \& Craver, C. F. (2000). Thinking about mechanisms. Philosophy of Science, $67(1), 1-25$.

Marbach-Ad, G., \& Stavy, R. (2000). Students' cellular and molecular explanations of genetic phenomena. Journal of Biological Education, 34(4), 200.

Mathewson, J. H. (1999). Visual-spatial thinking: An aspect of science overlooked by educators. Science Education, 83(1), 33-54. 
Mayr, E. (1961). Cause and effect in biology. Science, 134(3489), 1501-1506.

Mayr, E. (1996). The autonomy of biology: The position of biology among the sciences. The Quarterly Review of Biology, 71(1), 97-106.

McGill, G. (2008). Molecular movies... coming to a lecture near you. Cell, 133(7), 1127-1132.

Michelle, C., Eric, N. W., \& Glenda, C. (2008). The influence of prior knowledge on viewing and interpreting graphics with macroscopic and molecular representations. Science Education, 92(5), 848-867.

Moore, J. A. (1993). Science as a way of knowing: The foundations of modern biology. Cambridge: Harvard University Press.

Morange, M. (1998). A history of molecular biology (M. Cobb, Trans.). Cambridge: Harvard University Press.

Morange, M. (2008). The death of molecular biology? History and Philosophy of the Life Sciences, 30(1), $31-42$.

Orphanides, G., \& Reinberg, D. (2002). A unified theory of gene expression. Cell, 108(4), 439-451.

Pfeffer, W. F. P. (1884). Locomotorische richtungsbewegungen durch chemische reize. Untersuchungen aus dem Botanischen Institut in Tübingen, 1, 363-482.

Powell, A., \& Dupré, J. (2009). From molecules to systems: The importance of looking both ways. Studies in History and Philosophy of Science Part C: Studies in History and Philosophy of Biological and Biomedical Sciences, 40(1), 54-64.

Rappoport, L. T., \& Ashkenazi, G. (2008). Connecting levels of representation: Emergent versus submergent perspective. International Journal of Science Education, 30(12), 1585-1603.

Richardson, R. C., \& Stephan, A. (2007). Mechanism and mechanical explanation in systems biology. In F. C. Boogerd, F. J. Bruggeman, J. H. S. Hofmeyr, \& H. V. Westerhoff (Eds.), Systems biology: Philosophical foundations. Amsterdam: Elsevier.

Russ, R. S., Scherr, R. E., Hammer, D., \& Mikeska, J. (2008). Recognizing mechanistic reasoning in student scientific inquiry: A framework for discourse analysis developed from philosophy of science. Science Education, 92(3), 499-525.

Schönborn, K. J., \& Anderson, T. R. (2006). The importance of visual literacy in the education of biochemists. Biochemistry and Molecular Biology Education, 34(2), 94-102.

Silverman, M., \& Simon, M. (1977). Identification of polypeptides necessary for chemotaxis in Escherichia coli. Journal of Bacteriology, 130(3), 1317-1325.

Skipper, J. R. A., \& Millstein, R. L. (2005). Thinking about evolutionary mechanisms: Natural selection. Studies in History and Philosophy of Science Part C: Studies in History and Philosophy of Biological and Biomedical Sciences, 36(2), 327-347.

Tabery, J. G. (2004). Synthesizing activities and interactions in the concept of a mechanism. Philosophy of Science, 71(1), 1-15.

Tamir, P., \& Zohar, A. (1991). Anthropomorphism and teleology in reasoning about biological phenomena. Science Education, 75(1), 57-67.

Venville, G. J., \& Treagust, D. F. (1998). Exploring conceptual change in genetics using a multidimensional interpretive framework. Journal of Research in Science Teaching, 35(9), 1031-1055.

Verhoeff, R. P., Boerwinkel, D. J., \& Waarlo, A. J. (2009). Genomics in school. EMBO Reports, 10(2), $120-124$.

Verhoeff, R. P., Waarlo, A. J., \& Boersma, K. T. (2008). Systems modelling and the development of coherent understanding of cell biology. International Journal of Science Education, 30(4), 543-568.

Wilensky, U., \& Resnick, M. (1999). Thinking in levels: A dynamic systems approach to making sense of the world. Journal of Science Education and Technology, 8(1), 3-19.

Wimsatt, W. C. (1972). Complexity and organization. PSA: Proceedings of the Biennial Meeting of the Philosophy of Science Association, 1972, 67-86.

Woodward, J. (2010). Scientific Explanation. In E. N. Zalta (Ed.), The Stanford Encyclopedia of Philosophy (Spring 2010 Edition). http://plato.stanford.edu/archives/spr2010/entries/scientific-explanation/.

Yarden, H., \& Yarden, A. (2010). Learning using dynamic and static visualizations: Students' comprehension, prior knowledge and conceptual status of a biotechnological method. Research in Science Education, 40(3), 375-402.

Zohar, A., \& Ginossar, S. (1998). Lifting the taboo regarding teleology and anthropomorphism in biology education-Heretical suggestions. Science Education, 82(6), 679-697. 